\title{
ÚNG DỤNG PHƯƠNG PHÁP ĐO LƯờnG BÃO HÒA OXY MÁU TĨNH MẠCH TRỘN SV̄O TRONG HỒI SÚC HUYẾT ĐộNG BỆNH NHÂN PHẪU THUẬT TIM
}

\author{
Huỳnh Văn Minh*, Đoàn Đức Hoằng*, Lê Nhật Anh*, Võ Đại Quyền*, Phạm Văn Huệ*
}

\section{I. ĐẠTT VẤN ĐỀ}

Quá trình oxy hóa mô cơ quan đầy đủ có vai trò bảo đảm chức năng sống của cơ thể người. Tuy nhiên, người thầy thuốc thường gặp nhiều khó khăn trong việc đánh giá quá trình này ở những bệnh nhân hồi sức. Nhờ sự phát triển kỹ thuật công nghệ đo lường huyết động và bão hòa oxy máu tĩnh mạch trộn $\mathrm{S} \overline{\mathrm{V}} \mathrm{O}_{2}$ (mixed venous oxygen saturation), mà các bác sĩ lâm sàng có thêm phương tiện để đánh giá sự oxy hóa mô trên những bệnh nhân này. Nếu việc theo dõi cung lượng tim và khí máu động mạch giúp đánh giá khả năng cung cấp oxy của cơ thể, thì việc theo dõi bão hòa oxy máu tĩnh mạch trộn $\mathrm{S}_{\mathrm{V}} \mathrm{O}_{2}$ phản ánh cân bằng cung - cầu oxy của cơ thể. Nó phản ánh tình trạng sinh lý bệnh của hệ thống phổi và tuần hoàn, vì $\mathrm{S} \overline{\mathrm{V}} \mathrm{O}_{2}$ phản ánh lượng oxy dự trữ của cơ thể sau khi đã qua quá trình phân tách oxy tại hệ thống mao mạch cho mô cơ quan.

Kỹ thuật đo lường bão hòa oxy máu tĩnh mạch trộn $\mathrm{S}_{\bar{v}} \mathrm{O}_{2}$ được thực hiện bởi catheter Edwward Swan-Ganz Oximetry TD là một loại catheter động mạch phổi cải tiến đã được chứng nhận bởi FDA và đã được áp dụng tại các nước trên thế giới. Sự phát triển loại catheter động mạch phổi kết hợp với kỹ thuật đo lường oxy bằng sợ quang học cho phép người thầy thuốc theo dõi $S \bar{v} \mathrm{O}_{2}$ liên tục. Bảo hòa oxy máu tĩnh mạch trộn $\mathrm{S} \overline{\mathrm{V}} \mathrm{O}_{2}$ được đo từ máu trong động mạch phổi sau khi đã được trộn lẫn từ các nguồn máu tĩnh mạch trở về tim thông qua tĩnh mạch chủ trên, tĩnh mạch chủ dưới, từ xoang vành và từ các buồng tim phải. Như vậy, $\mathrm{S} \overline{\mathrm{V}} \mathrm{O}_{2}$ biểu thị giá trị trung bình về độ bảo hòa oxy máu tĩnh mạch của tất cả các cơ quan và mô cơ thể. Kỹ thuật theo dõi $S \bar{v} O_{2}$ đã được cho là một phương thức theo dõi huyết động an toàn, thuận tiện và có độ tin cậy cao. Phương thức theo dõi diễn biến sinh lý huyết động này rất có ý nghĩa nhằm tìm hiểu hàng loạt những rối loạn về cân bằng cung - cầu oxy; phát hiện và chẩn đoán nhanh chóng những biến đổi bệnh lý; cũng như giúp hướng dẫn đưa ra liệu pháp điều trị can thiệp kịp thời. Điều này đặc biệt hữu ích trong hồi sức huyết động cho các bệnh nhân hồi sức, đặc biệt những bệnh nhân mổ tim vốn có rất nhiều nguy cơ đe dọa đến tình trạng huyết động và đe dọa quá trình oxy hóa của cơ thể. Tuy nhiên, cho đến nay, vẫn chưa có nhiều nghiên cứu sử dụng kỹ thuật $\mathrm{S} \overline{\mathrm{V}} \mathrm{O}_{2}$ trong lĩnh vực hồi sức phẫu thuật tim, nhất là chưa có nghiên cứu đi sâu về mục đích cuối cùng trong lĩnh vực hồi sức tim phổi là nhằm đảm bảo việc cung cấp oxy đầy đủ đáp ứng thỏa đáng nhu cầu chuyển hóa của mô và các cơ quan trong cơ thể. Chính vì vậy, chúng tôi thực hiện chuyên đề "Phuơng pháp đo luờng và ưng dụng bão hòa oxy máu tĩnh mạch trộn $\mathrm{S} \overline{\mathrm{V}} \mathrm{O}_{2}$ trong hồi súc huyêt động bệnh nhân phẫu thuật tim" nhằm tìm hiểu:

1. Kỹ thuật đo lường bão hòa oxy máu tĩnh mạch trộn $\mathrm{S} \overline{\mathrm{V}} \mathrm{O}_{2}$ trong thăm dò huyết động.

2. Úng dụng lâm sàng của kỹ thuật đo lường bão hòa oxy máu tĩnh mạch trộn $\mathrm{S} \overline{\mathrm{V}} \mathrm{O}_{2}$ trong hồi sức huyết động bệnh nhân phẫu thuật tim

\section{PHƯƠNG PHÁP ĐO LƯỜNG BÃO HÒA OXY MÁU TĨNH MẠCH TRỘN SV̄O}

Bão hòa oxy máu tĩnh mạch trộn $\mathrm{S} \mathrm{O}_{2}$ biểu thị kết quả của quá trình vận chuyển và tiêu thụ oxy ở mô: $\mathrm{S} \mathrm{O}_{2}=$ oxy được vận chuyển đến mô - oxy tiêu thụ tại mô

Khi có nguy cơ đe dọa cân bằng cung - cầu oxy, cơ thể sẽ huy động các cơ chế hoạt động bù, và hiệu quả của các hoạt động này được phản ánh lập tức bởi giá trị của $\mathrm{S} \bar{v} \mathrm{O}_{2}$ đo được. Nếu giá trị $\mathrm{S} \overline{\mathrm{V}} \mathrm{O}_{2}$ bình thường, có nghĩa là lượng oxy được cung cấp đầy đủ cho mô. Tuy nhiên, nếu giá trị $\mathrm{S} \mathrm{V}_{2}$ thấp thì hoặc là do cung cấp oxy không đủ, hoặc là do nhu cầu tiêu thụ oxy tăng cao. Cho dù nguyên nhân nào thì nếu giá trị $\mathrm{S}_{\bar{V}} \mathrm{O}_{2}$ giảm thấp là dấu chỉ điểm rằng cơ thể đang ở ranh giới cuối cùng để phòng vệ và duy trì cân bằng cung - cầu oxy; và chúng ta cần phải can thiệp kịp thời.

\footnotetext{
* Trung tâm Tim mạch, Bệnh viện Trung Uơng Huế. Ngườ chịu trách nhiệm khoa họ: ThS. Đoàn Đức Hoằng Ngày nhận bài: 20/07/2015 - Ngày Cho Phép Đăng: 20/08/2015 Phản Biện Khoa học: PGS.TS. Đặng Ngoc Hùng
} PGS.TS. Lê Ngọc Thành 
2.1. Kỹ thuật đo lường bão hòa oxy máu tĩnh mạch trộn $\mathrm{S} \overline{\mathrm{V}} \mathrm{O}_{2}$
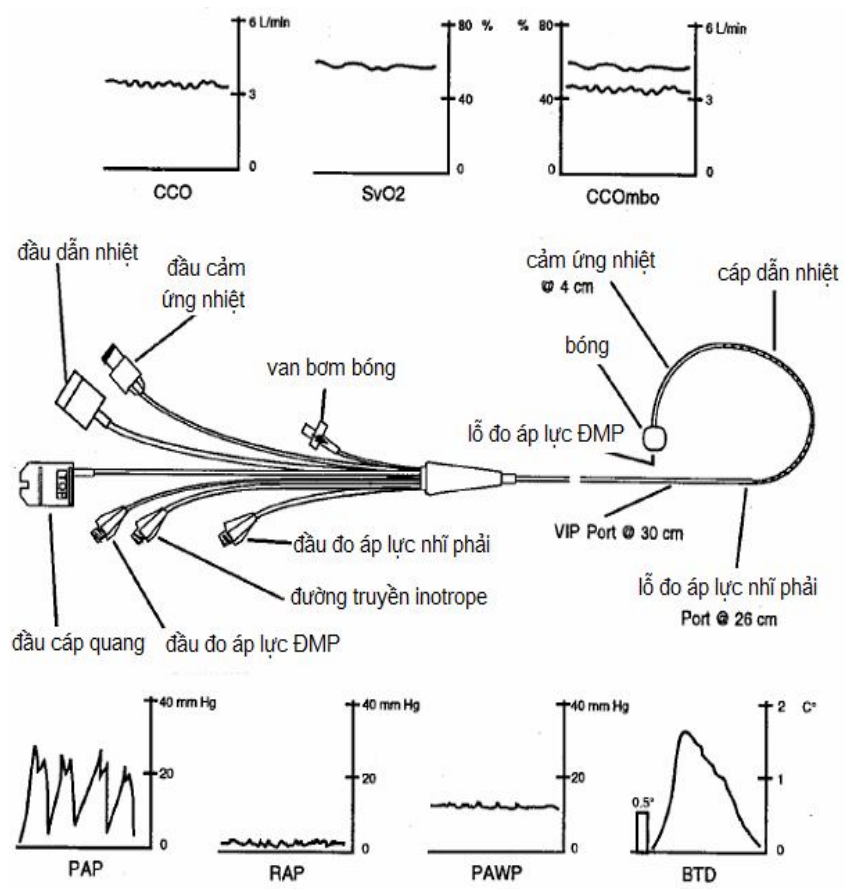

Hình 1. Catheter Swan-Ganz Oxymetry TD

Bão hòa oxy máu tĩnh mạch trộn $\mathrm{S} \mathrm{O}_{2}$ được đo từ máu trong động mạch phổi. Quan trọng là phải lấy mẫu máu sau khi đã trộn lẫn các nguồn máu tĩnh mạch trở về từ tĩnh mạch chủ trên, tĩnh mạch chủ dưới, và máu từ xoang vành. Bão hòa oxy máu tĩnh mạch trộn $\mathrm{S} \overline{\mathrm{V}} \mathrm{O}_{2}$ có thể được theo dõi liên tục bởi hệ thống Swan-Ganz Oxymetry TD System; hệ thống này còn có thể đo cung lượng tim ngắt quảng hoặc đo cung lượng tim liên tục theo nguyên lý pha loãng nhiệt độ bằng kỹ thuật catheter CCOmbo (hình 1).

Kỹ thuật đo lường bão hòa oxy máu tĩnh mạch trộn $\mathrm{S}^{-} \mathrm{O}_{2}$ dựa theo nguyên lý đo phổ quang của tia phản chiếu (reflection spectrophotometry) (hình 2). Sự lan truyền ánh sáng có bước sóng thích hợp qua một sợi quang học được tích hợp trong thân catheter cho đến đầu mút catheter đang được đặt trong mạch máu. Ánh sáng phản chiếu sau đó được dẫn truyền trở lại qua một sợi quang học thứ hai về bộ phận phân tách sóng quang ở trong module quang học. Module quang học này được kết nối vào monitor theo dõi bởi một cáp dẫn truyền tín hiệu. Vì phân tử hemoglobin và oxyhemoglobin có khả năng hấp thu các tia sáng có các bước sóng khác nhau, nên ánh sáng phản chiếu có thể được phân tích nhằm xác định tỉ lệ phần trăm bão hòa oxy máu tĩnh mạch trộn \% $\mathrm{S} \overline{\mathrm{V}} \mathrm{O}_{2}$.

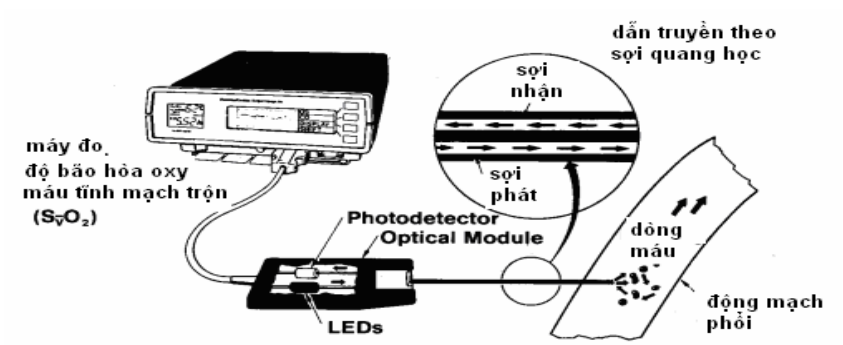

Hình 2. Nguyên lý đo phổ quang tia phản chiếu.

Có hai loại tia sáng có bước sóng thích hợp được chụp phổ quang tùy thuộc vào đặc tính hấp thu ánh sáng của hemoglobin và oxyhemoglobin. Một loại bước sóng là nhạy cảm với những biến đổi của bão hòa oxy, còn loại còn lại thì không.

2.2. Những tình trạng bệnh lý làm thay đổi bất thường giá trị $\mathrm{S} \overline{\mathrm{V}} \mathrm{O}_{2}$

Trong giới hạn bình thường của giá trị $\mathrm{SV}_{\mathrm{V}}$ (khoảng $60-80 \%$ ), người thầy thuốc có thể đánh giá sự tưới máu mô là đây đủ. Nếu $\mathrm{S} \overline{\mathrm{V}} \mathrm{O}_{2}<60 \%$ thì cần nghĩ đến giảm phân tách oxy và/hoặc do tăng tiêu thụ oxy. Nếu $\mathrm{S}_{\bar{v}} \mathrm{O}_{2}<40 \%$, khả năng hoạt động bù của cơ thể bị hạn chế, và oxy không đủ để đáp ứng nhu cầu của mô. Bảng 4 minh họa những trường hợp lâm sàng gây nên mất cân bằng cung - cầu oxy.

Bảng 1. Úng dụng lâm sàng của việc theo dõi chỉ số $S \bar{v} O_{2}$

\begin{tabular}{|c|c|c|c|}
\hline \multirow{6}{*}{$\begin{array}{l}\mathrm{SV} \mathrm{O}_{2} \\
\text { tăng }\end{array}$} & \multirow{2}{*}{\multicolumn{2}{|c|}{ Tăng vận chuyển oxy }} & Tăng $\mathrm{FiO}_{2}$ \\
\hline & & & Tăng oxy hóa \\
\hline & \multirow{4}{*}{\multicolumn{2}{|c|}{ Giảm nhu cầu tiêu thụ oxy }} & Hạ thân nhiệt \\
\hline & & & Gây mê sâu \\
\hline & & & Thuốc giãn cơ, liệt cơ \\
\hline & & & Nhiễm trùng \\
\hline \multirow{5}{*}{$\begin{array}{l}\mathrm{SV}_{2} \mathrm{O}_{2} \\
\text { giảm }\end{array}$} & \multirow{3}{*}{$\begin{array}{l}\text { Giảm } \\
\text { vận } \\
\text { chuyển } \\
\text { oxy }\end{array}$} & Giảm $\mathrm{Hb}$ & Thiếu máu, chảy máu \\
\hline & & Giảm $\mathrm{SaO}_{2}$ & Thiếu oxy tố chức \\
\hline & & $\begin{array}{l}\text { Giảm cung } \\
\text { lượng tim }\end{array}$ & $\begin{array}{l}\text { Giảm thế tích, sốc, } \\
\text { loạn nhịp }\end{array}$ \\
\hline & \multirow{2}{*}{\multicolumn{2}{|c|}{ Tăng nhu cầu tiêu thụ oxy }} & Tăng thân nhiệt, đau \\
\hline & & & Run lanh, co giât \\
\hline
\end{tabular}

Trường hợp $\mathrm{S}_{\mathrm{V}} \mathrm{O}_{2}>80 \%$ có thể do tăng cung cấp và/hoặc do giảm nhu cầu tiêu thụ oxy. Tăng cung cấp oxy có thể do tăng nồng độ oxy trong khí thở vào (tăng $\mathrm{FiO}_{2}$ ). Giảm tiêu thụ oxy có thể gặp trong trường hợp hạ thân nhiệt, hoặc ở những bệnh nhân được gây mê sâu, và đang được thở máy hoặc sử dụng thuốc giãn cơ.

Kỹ thuật đặt catheter để đo áp lực động mạch phổi bít cũng có thể gây tăng giả tạo giá trị $\mathrm{S} \overline{\mathrm{V}} \mathrm{O}_{2}$. Nếu đo giá trị $\mathrm{S} \overline{\mathrm{V}} \mathrm{O}_{2}$ trong quá trình đang bơm phồng bóng ở đầu xa catheter để đo áp lực động mạch phổi bít PAWP, thì bóng phồng sẽ chặn dòng máu phía trước từ thất phải tống lên. Trường hợp này máu ở đầu xa catheter phía sau bóng phồng bị ứ đọng và sẽ tiếp tục 
hấp thu oxy từ môi trường giàu oxy xung quanh các phế nang làm cho bão hòa oxy tăng cao xâp xỉ với máu động mạch. Tuy nhiên, trường hợp tăng bão hòa oxy máu tĩnh mạch $\mathrm{S}_{\bar{v}} \mathrm{O}_{2}$ nhân tạo này chỉ thoáng qua trong quá trình đo áp lực động mạch phổi bít và sẽ biến mất sau khi xả xẹp bóng.

Giá trị bão hòa oxy máu tĩnh mạch trộn có thể dao động từ bình thường đên tăng cao trong 1 số bệnh lý làm ảnh hưởng đến quá trình oxy hóa mô. Có 3 cơ chế bệnh sinh trong những trường hợp này: do trộn lẫn với máu động mạch; do bất thường tái phân bố tưới máu trong một số trường hợp; và do thiếu oxy mô gây độc tế bào.

- Trộn lẩn giữa máu tĩnh mạch và máu động mạch do hiện diện của luồng thông (shunt) giữa động - tĩnh mạch : trường hợp này tổng lượng oxy được vận chuyển (cung lượng tim $x$ nồng độ oxy máu động mạch: $\mathrm{QT}_{(\text {total }} \times \mathrm{CaO}_{2}$ ) được chia làm 2 phần : một phần là lượng oxy thật sự được vận chuyển đến mao mạch để phân tách cho mô $\left(\mathrm{Qc}_{\text {(capiliary) }} \times \mathrm{CaO}_{2}\right)$; lượng oxy còn lại được vận chuyển qua luông thông (shunt) nối tắt giữa động - tĩnh mạch mà không đi qua mô $\left(\mathrm{Qs}_{\text {(shunt) }} \times \mathrm{CaO}_{2}\right)$ (hình 3).

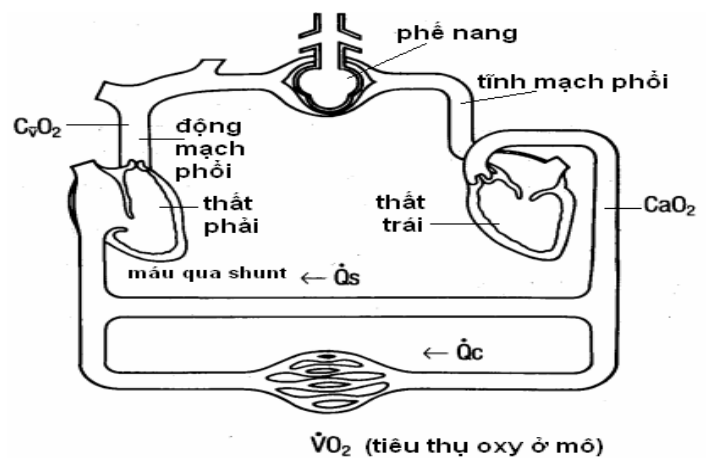

\section{Hình 3. Trộn lẫn máu động mạch do shunt động mạch - tĩnh mạch.}

Sự phân chia luồng máu làm giảm lượng oxy vận chuyển thật sự đến mô, do đó tiêu thụ oxy bị giới hạn và nhu cầu oxy mô không được đáp ứng. Kêt quả làm tăng quá trình thiếu oxy mô. Tuy nhiên, luồng máu qua shunt có giá trị $S \bar{v} \mathrm{O}_{2}$ như trong máu động mạch vì nó chảy tắt không qua mô. Nồng độ oxy máu tĩnh mạch trộn lúc này phản ánh sự trộn lẫn giữa luồng máu giàu oxy từ shunt và luồng máu sau khi rời mô. Đây là nguyên nhân tăng $\mathrm{S} \mathrm{O}_{2}$ trong khi đang diễn ra quá trình thiếu oxy ở mô. Hiện tượng này được giải thích là một trong những cơ chế xảy ra trong bệnh lý sốc nhiễm trùng.

- Những bất thường phân bố lưu lượng máu góp phần làm gia tăng giá trị $\mathrm{S} \overline{\mathrm{V}} \mathrm{O}_{2}$ trong trường hợp vận chuyển oxy không đủ. Trong một số điều kiện, cơ thể đáp ứng hoạt động bù bằng cách hạn chế lưu lượng máu đên mồ có nhu cầu oxy thấp để cung cấp lưu lượng bổ sung cho mô có nhu cầu oxy cao hơn. Nếu sự tái phân bô tưới máu không xảy ra thì sẽ có hiện tượng thiếu oxy ở các mô không nhận đủ oxy trong khi ở các mô có nhu cầu oxy thấp thì lại được tưới máu quá mức. Máu trở về sau khi qua các mô có nhu cầu oxy thấp sẽ có nồng độ oxy cao gây tăng $\mathrm{S} \mathrm{O}_{2}$ cho dù các mô khác bị thiếu oxy.

- Thiếu oxy mô do ngộ độc tế bào: giảm tiêu thụ oxy có thể do ở các mô có các men oxy hóa (oxydative enzymes) bi bất hoạt hoặc chỉ còn một phần chức năng. Điều này dẫn đến nồng độ oxy trong máu sau khi qua mô vẫn cao xấp xỉ trong máu động mạch và $\mathrm{S} \mathrm{O}_{2}$ tăng cao. Tuy nhiên, các mô lại bị chết do thiếu oxy. Cơ chể này được cho là thiếu oxy do ngộ độc tế bào và điều này được tìm thấy ở bệnh nhân ngộ độc cyanide do sử dụng liệu pháp điều trị với nitroprusside.

Khi sử dụng phương tiện theo dõi bão hòa oxy máu tĩnh mạch trộn $\mathrm{S} \bar{v} \mathrm{O}_{2}$ liên tục, người thầy thuốc cần lưu ý tất cả những lần đo mà chỉ số $\mathrm{S} \overline{\mathrm{V}} \mathrm{O}_{2}$ có giá trị nằm ngoài giới hạn bình thường. Ngoài ra, bất kỳ một biến đổi $>10 \%$ giá trị của chỉ số $\mathrm{S}_{\bar{v}} \mathrm{O}_{2}$ so với giá trị đo được trước đó (kể cả giá trị đo được lần này còn trong giới hạn bình thường) cũng cần phải được cân nhắc và phân tích kỹ nếu như giá trị bất thường này tồn tại kéo dài >3-5 phút. Trong trường hợp có sự biến đổi giá trị $\mathrm{SV} \mathrm{O}_{2}$, người thầy thuốc cần phải xác định nguyên nhân cu thể bằng cách thăm khám và đánh giá tât cả những yếu tố ảnh hưởng đến cân bằng cung cầu oxy và cần phải có can thiệp điều trị kịp thời.

\subsection{Thay đổi $\mathrm{S} \bar{v} \mathrm{O}_{2}$ do sự di chuyển của đầu catheter động mạch phổi}

Catheter đo lường chỉ số oxy cũng có thể bị đẩy vào sâu trong mạch máu phổi. Khi đó giá trị bão hòa oxy sẽ bị ảnh hưởng bởi đặc tính hấp thu của thành mạch máu, và đo lường $S \bar{v} \mathrm{O}_{2}$ có thể không chính xác trong một số trường hợp. Vì vậy, các thương tổn do sự dịch chuyển catheter có thể xảy ra do tắc nghẽn kéo dài hoặc do mạch máu bị căng dãn quá mức do bơm bóng catheter. Dịch chuyển đầu catheter thường được phát hiện bằng cách theo dõi đổi bất thường các giá trị áp lực đo ở lồ xa phía đầu catheter và bởi hình ảnh trên phim x-quang. Tuy nhiên đối với loại catheter đo lường chỉ số oxy hóa, thì các sợi quang học có thể được dùng để phát hiện khu vực ngoại vi của mạng mạch máu phổi. Dẫn truyền ánh sánh được sử dụng để đo $\mathrm{S} \overline{\mathrm{V}} \mathrm{O}_{2}$ còn có thể lan truyền đến tiếp xúc thành mạch máu, đặc biệt trong trường hợp đầu catheter được đẩy quá xa vào trong các mạch máu nhỏ. Hệ thống đo lường chỉ số oxy hóa Edwards có thể phát hiện tình trạng này bằng cách báo động dấu hiệu nhịp đập do thành động mạch co bóp.

Đầu catheter thường dịch chuyển trong quá trình thao tác phẫu thuật tim. Điều này có thể gặp khi bệnh nhân cử động và/hoặc kích thích trong quá trình thở máy. Giải pháp đặt lại vị trí catheter bằng cách xả xẹp bóng và kéo lùi catheter từ $1-3 \mathrm{~cm}$. Kiểm tra lại vị trí của áp lực động mạch phổi bít bằng cách bơm phồng bóng ở đầu catheter cho đến khi đạt được dạng sóng áp lực động mạch phổi bít PAWP. Nếu giá trị PAWP đã đạt được với thể tích bơm bóng $1,25 \mathrm{ml}$, thì cần tiếp tục 
kéo lùi catheter sao cho vẫn được giá trị PAWP nhưng với thể tích bơm bóng đủ $1,5 \mathrm{ml}$. Khi điều chỉnh lại vị trí catheter cần phải thực hiện các thao tác sau: 1) điều chỉnh lại báo động dấu hiệu nhịp đập động mạch; 2) điều chỉnh độ chính xác đo lường giá tri $\mathrm{S}_{\bar{v}} \mathrm{O}_{2} ; 3$ ) giảm thiểu nguy cơ gây vỡ động mạch phổi và/hoặc nhồi máu phồi; 4) điều chỉnh độ chính xác khi đo cung lượng tim và giá trị áp lực động mạch phổi bít PAWP. Để có được các thông tin với độ tịn cậy cao nhất, cần thực hành tốt một cách định kỳ việc kiểm tra vị trí đầu catheter trong quá trình theo dõi huyết động của bệnh nhân. Có nhiêu cách để phát hiện sự dịch chuyển đầu catheter động mạch phổi với các thao tác cơ bản sau:

- Theo dõi áp lực đầu xa của catheter: nếu đường biểu diễn sóng áp lực động mạch phổi bít PAWP vẫn đạt được sau khi đã xả xẹp bóng thì có nghĩa là đầu catheter đã bị dịch chuyển vào sâu. Sự xuât hiện đột ngột một hành động bởi thông khí nhân tạo lên hình dạng sóng áp lực cũng cần nghĩ đến sự dịch chuyển đầu catheter.

Theo dõi thể tích bơm bóng cần thiết để đạt được giá trị áp lực động mạch phổi bít PAWP. Nếu đạt được PAWP chỉ với thể tích bơm bóng dưới $1,25 \mathrm{ml}$, thì đẩu catheter thường ở vị trí không tốt. Lúc này, đầu catheter thường ở vị trí trong các mạch máu nhỏ hoặc ở đoạn hợp lưu (bifurcation) giữa 2 nhánh động mạch phổi, và ở vị trí này có thể ảnh hưởng đến độ chính xác khi đo giá trị bão hòa oxy máu tính mạch trộn $\mathrm{S}_{\bar{v}} \mathrm{O}_{2}$.

- Quan sát giá trị $\mathrm{S}_{\bar{v}} \mathrm{O}_{2}$ ở các thời điểm trước, trong và sau khi thực hiện thao tác đo áp lực động mạch phổi bít PAWP. Giai đoạn bơm phồng bóng catheter, giá trị $\mathrm{S} \overline{\mathrm{V}} \mathrm{O}_{2}$ thường tăng nhanh và đột ngột phản ánh tình trạng máu môi trường giàu oxy xung quanh phế nang. Giai đoạn xả xẹp bóng, giá trị $\mathrm{S}_{\bar{V}} \mathrm{O}_{2}$ trở về các trị số ban đầu ở giai đoạn trước khi đo áp lực động mạch phổi bít PAWP. Nếu những thay đổi này không xảy ra, thì cần cân nhắc điều chỉnh lại vị trí của catheter động mạch phổi, ngay cả trong trường hợp vẫn đạt được giá trị áp lực động mạch phổi bít PAWP.

- Theo dõi báo động và cường độ nhịp đập động mạch. Khi có báo động này, đặc biệt nếu xuất hiện biểu hiện kể trên, thì khả năng rất lớn có sự dịch chuyển đầu catheter vào sâu làm ảnh hưởng đến giá trị đo lường bão hòa oxy máu tĩnh mạch trộn $\mathrm{S} \mathrm{O}_{2}$.

\section{III. ÚNG DỤNG LÂM SÀNG CỦA KỸ THUẬT ĐO LƯờiNG $\mathrm{S} \mathrm{O}_{2}$}

Bão hòa oxy máu tĩnh mạch trộn $\mathrm{SV} \mathrm{O}_{2}$ là một chỉ điểm nhạy về tình trạng bệnh nhân và thường biểu hiện trước khi xuất hiện các chỉ điểm khác về tình trạng bệnh lý tim phổi không ổn định. Phương pháp theo dõi liên tục $\mathrm{S} \overline{\mathrm{V}} \mathrm{O}_{2}$ giúp báo động cho người thầy thuốc về những biến đồi tình trạng người bệnh sớm hơn so với các phương thức truyền thống trước đây, qua đó giúp chẩn đoán và chơn liệu pháp điều trị can thiệp sớm hơn trong diễn tiển lâm sàng trên người bệnh. Về cơ bản, theo dõi giá trị $\mathrm{S}_{\bar{v}} \mathrm{O}_{2}$ là:
- Hệ thống theo dõi và cảnh báo sớm tình trạng huyết động người bệnh

- Hướng dẫn để điều chỉnh và đánh giá liệu pháp điều trị

- Phương tiện để phân tích những biến đổi khác trên người bệnh.

\subsection{Vai trò của chỉ số $\mathrm{S}$ V̄O $\mathrm{O}_{2}$ trong theo dõi và cảnh báo sớm rối loạn huyết động}

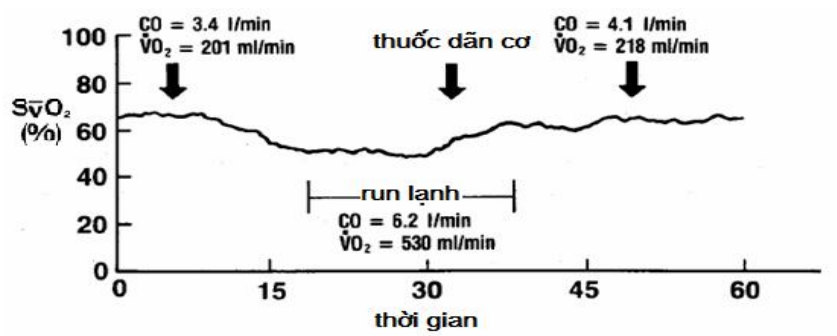

Hình 4. Úng dụng lâm sàng của chỉ số $S \bar{v} O_{2}$ trong điều trị sau mổ

Hình 4 mô tả khả năng duy trì bão hòa oxy máu tĩnh mạch trộn $\mathrm{SV} \mathrm{O}_{2}$ trong giới hạn bình thường trong suốt quá trình phẫu thuật kéo dài, nhưng khi chuyển bệnh nhân trở về phòng hồi sức thì giá trị $\mathrm{S} \mathrm{O}_{2}$ giảm dột ngột còn $50 \%$. Theo suy diễn thông thường thì tình trạng này có thể do cung lượng tim bị giảm sau tác động của quá trình phẫu thuật kéo dài. Tuy nhiên, khi đo cung lượng tim theo phương pháp pha lõang nhiệt độ thì thấy cung lượng tim ở thời điểm này đã tăng đáng kể $(6,2$ lít/phút). Quá trình thăm khám phát hiện bệnh nhân bị run lạnh ở giai đoạn hồi tỉnh đã làm tăng tiêu thụ oxy do tăng nhu cầu chuyển hóa $(530 \mathrm{ml}$ $\mathrm{O}_{2} /$ phút), mặc dù cơ thể đã đáp ứng trước đó với tình trạng này bằng cách tăng cung lượng tim. Trường hợp này can thiệp điều trị với liệu pháp thuốc giãn cơ làm giảm tiêu thụ oxy về giới hạn bình thường. Điều này giúp loại trừ yếu tố làm tăng nhu cầu tiêu thụ oxy, vì vậy cung lượng tim $\mathrm{CO}$ và Bão hòa oxy máu tĩnh mạch trộn $\mathrm{S}_{\bar{v}} \mathrm{O}_{2}$ trở về trong giới hạn bình thường.

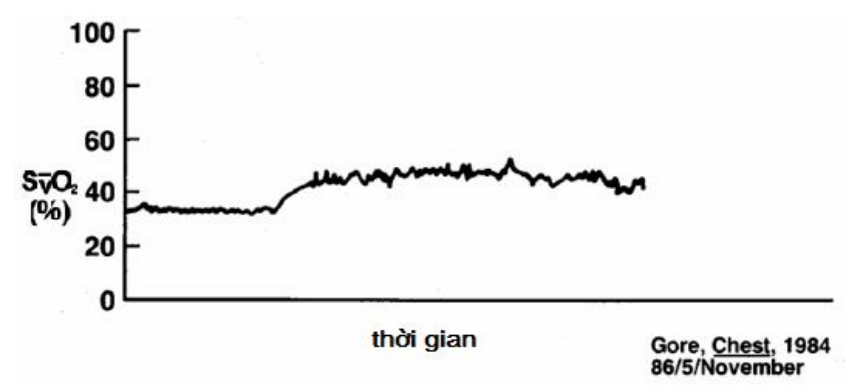

Hình 5. Úng dụng lâm sàng chỉ số $\mathrm{S} \overline{\mathrm{v}} \mathrm{O}_{2}$ trong điều trị sốc nhiê̂m khuẩn

Hình 5 mô tả tình trạng trụy tim mạch nghiêm trọng với bão hòa oxy máu tĩnh mạch trộn $\mathrm{S} \mathrm{O}_{2}$ giảm rất thấp còn $35 \%$. Nhiều liệu pháp điều trị tăng cường đã được sử dụng nhưng không cải thiện bệnh. Sau vài 
giờ, giá trị $\mathrm{S} \mathrm{O}_{2}$ tăng nhưng không xác định được nguyên nhân. Nguyên nhân được tìm thấy sau đó là bệnh nhân bị sốt cao và kết quả cấy máu bệnh nhân bị nhiễm trùng huyết.

Trong trường hợp này, giá trị $\mathrm{S} \overline{\mathrm{v}} \mathrm{O}_{2}$ tăng trở lại trong giới hạn bình thường không phải là dấu hiệu cải thiện tình trạng bệnh. Mà đó là tình trạng mở shunt động - tĩnh mạch ngoại vi do cơ chế bệnh sinh của sốc nhiểm khuẩn làm tăng một lượng lớn máu giàu bão hòa oxy trở về tim. Tình trạng cung lượng tim tăng cao và kháng lực mạch máu ngoại biên giảm thấp phù hợp với bệnh lý sốc nhiễm khuẩn. Sự gia tăng giá trị $\mathrm{S} \overline{\mathrm{V}} \mathrm{O}_{2}$ trong giai đoạn sớm đang xảy ra tình trạng trụy tim mạch là một chỉ điểm tốt giúp phát hiện bệnh lý sốc nhiễm khuẩn.

\subsection{Vai trò của $S \bar{v} \mathrm{O}_{2}$ hướng dẫn và đánh giá} hiệu quả liệu pháp điều trị huyết động

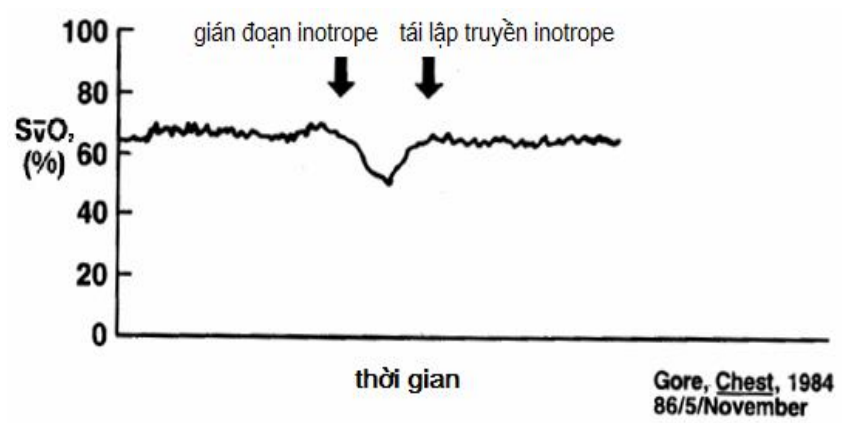

Hình 6. Úng dụng lâm sàng $\mathrm{S} \overline{\mathrm{v}} \mathrm{O}_{2}$ trong đánh giá hiệu quả liệu pháp inotrope

Hình 6 mô tả liệu pháp truyền tĩnh mạch dobutamine bị gián đoạn, giá trị $S \bar{v} \mathrm{O}_{2}$ giảm ngay lập tức và duy trì mức thấp cho đến khi đường truyền thuốc được tái thiết lập. Điều này phản ánh sự lệ thuộc thuốc của người bệnh để duy trì cung lượng tim.

Hình 7 mô tả ứng dụng lâm sàng của chỉ số $\mathrm{S} \mathrm{O}_{2}$ trong theo dõi và đánh giá hiệu quả của liệu pháp điều trị với một loại thuốc cải thiện chức năng tim khác là nitroprusside với mục đích làm giảm hậu gánh. Cách điều chỉnh liều thuốc nitroprusside theo từng nấc nhỏ (titration) đồng thời theo dõi cho đến khi có sự cải thiện bão hòa oxy máu tĩnh mạch trộn $\mathrm{S} \bar{v} \mathrm{O}_{2}$ và kiểm tra siêu âm thấy chức năng tim cải thiện đáng kể.

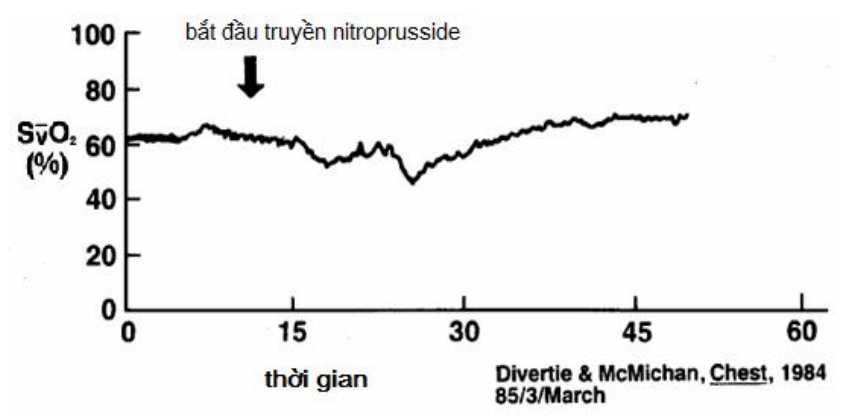

Hình 7. Úng dưng lâm sàng $S \bar{v} O_{2}$ trong đánh giá điều trị cải thiện hậu gánh
Theo dõi liên tục bão hòa oxy máu tĩnh mạch trộn $\mathrm{S} \overline{\mathrm{O}} \mathrm{O}_{2}$ cũng rất hữu ích trong việc theo dõi và đánh giá phương thức hỗ điều trị hỗ trợ chức năng hô hấp cho các bệnh nhân hồi sức. Hình 8 mô tả ích lợi của việc theo dõi $\mathrm{S} \mathrm{O}_{2}$ để tiến hành cai máy thở cho bệnh nhân. Trước đó bệnh nhân được duy trì chế độ thở máy với nồng độ oxy trong khí thở vào $\mathrm{FiO}_{2}=70 \%$ và giá trị của chỉ số $\mathrm{S} \overline{\mathrm{V}} \mathrm{O}_{2}$ duy trì trong giới hạn bình thường. Việc chủ động giảm dần giá trị $\mathrm{FiO}_{2}$ không làm giảm giảm đáng kể giá trị của chỉ số $\mathrm{SV}_{\mathrm{V}}$. Điều này có nghĩa việc giảm cung cấp oxy, thì người bệnh vẫn có đủ đảm bảo khả năng hoạt động vận chuyển oxy đến cho mô biểu hiện với kết quả khí máu vẫn tốt.

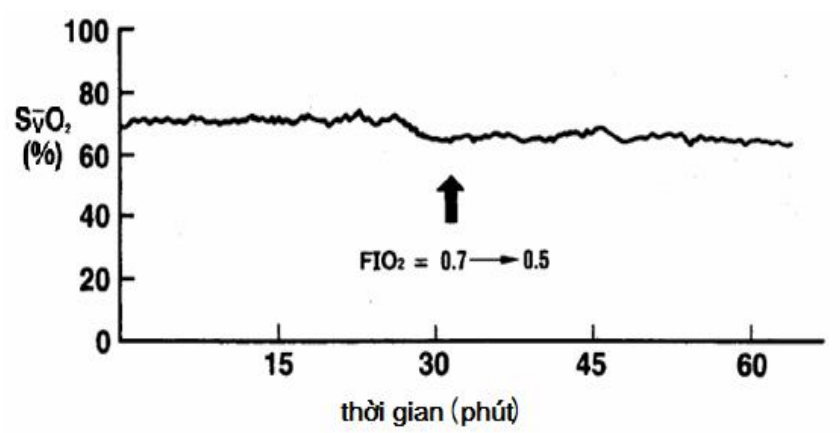

Hình 21. Úng dụng lâm sàng $S \bar{v} O_{2}$ trong đánh giá liệu pháp cai máy thở

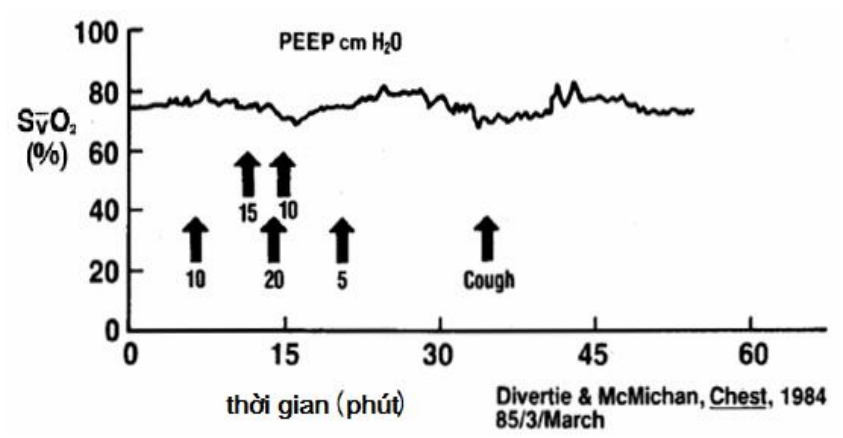

Hình 7. Úng dụng lâm sàng $S \bar{v} O_{2}$ trong thở máy áp luec duong

Bão hòa oxy máu tĩnh mạch trộn $\mathrm{S} \mathrm{O}_{2}$ là phương tiện thuận lợi và chính xác giúp điều chỉnh một cách nhanh chóng liệu pháp áp lực dương cuối thì thở ra PEEP để đạt được giá trị PEEP tối ưu mà không cần phải xét nghiệm khí máu và đo cung lượng tim nhiều lần. Vì trong nững trường hợp sử dụng PEEP cao, thường có mức $\mathrm{PEEP}>10 \mathrm{cmH}_{2} \mathrm{O}$, làm ảnh giảm cung lượng tim do đó ảnh hưởng đến ích lợi cải thiện khí máu của liệu pháp PEEP. Hình 22 mô tả phương thức điều chỉnh giá trị PEEP theo từng nấc nhỏ (titration) đồng thởi theo dõi giá trị của chỉ số $\mathrm{SV} \mathrm{O}_{2}$ để đánh giá ảnh hưởng của việc điều chỉnh PEEP lên cung lượng tim. 
Có những bệnh nhân sau phẫu thuật tim cần hỗ trợ tuần hoàn bằng kỹ thuật bơm bóng đối xung trong động mạch chủ IABP. Kỹ thuật bơm bóng làm tăng huyết áp tâm trương, làm giảm hậu gánh thất trái, làm tăng tưới máu vành, do đó làm giảm tiêu thụ oxy cơ tim và làm giảm thiếu máu cơ tim. Theo dõi liên tục giá trị bão hòa oxy máu tĩnh mạch trộn $\mathrm{SV}_{\mathrm{V}} \mathrm{O}_{2}$ có thể giúp đánh giá hiệu quả của liệu pháp trong giai đoạn cai máy IABP. Hình 9 mô tả biến thiên giá trị $\mathrm{S} \overline{\mathrm{V}} \mathrm{O}_{2}$ giai đoạn cai máy IABP từ tỉ lệ hỗ trợ bóng đối xung từ $1: 1$ sang tỉ lệ $1: 2$, thì giá trị $S \bar{v} \mathrm{O}_{2}$ tụt giảm rất đáng kể. Khi chuyển lại tỉ lệ hỗ trợ bóng đối xung $1: 1$ thì giá trị $\mathrm{S} \overline{\mathrm{V}} \mathrm{O}_{2}$ cải thiện trở lại. Giá trị Bão hòa oxy máu tĩnh mạch trộn $S \bar{V} \mathrm{O}_{2}$ phản ánh sự thay đổi huyết động trên người bệnh rất kịp thời.

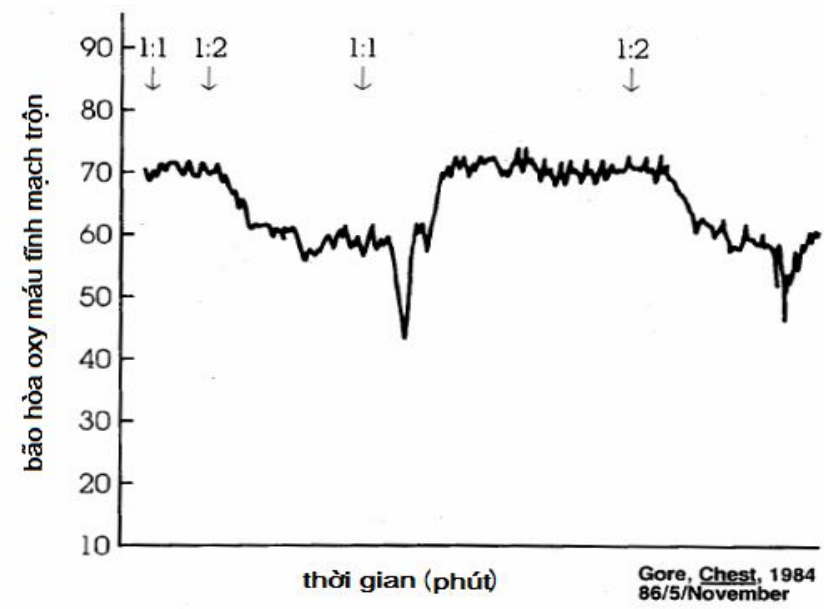

Hình 9. Ứng dụng lâm sàng $\mathrm{S} \bar{v} \mathrm{O}_{2}$ đánh giá hiệu quả của liệu pháp hô̂ trợ tuần hoàn bằng kỹ thuật bơm bóng đối xung trong động mạch chủ IABP

\subsection{Vai trò chỉ số $\mathrm{S} \overline{\mathbf{O}} \mathrm{O}_{2}$ trong đánh giá các biến đổi bệnh lý khác}

Một số trường hợp bệnh nhân có huyết áp bình thường nhưng cung lượng tim không đủ, và ngược lại đôi khi người bệnh có huyết áp bất thường nhưng vần có cung lượng tim đầy đủ. Theo dõi $\mathrm{S}^{\mathrm{V}} \mathrm{O}_{2}$ hỗ trợ người thầy thuốc xác định các trường hợp này.

Huyết áp tâm thu tụt có thể biểu hiện tình trạng tưới máu kém. Tuy nhiên, tụt huyết áp cũng có thể biểu thị tình trạng giãn mạch ngoại biên và cải thiện tưới máu. Các liệu pháp điều trị là hoàn toàn khác nhau trong hai trường hợp này. Nếu huyết áp giảm xuống $20 \mathrm{mmHg}$ so với trước nhưng giá trị $\mathrm{S} \overline{\mathrm{V}} \mathrm{O}_{2}$ không biến đổi hoặc vẫn còn trong giá trị bình thường thì không cần can thiệp điều trị. Tuy nhiên, nếu huyết áp cũng giảm tương đương nhưng kéo theo giá trị $\mathrm{S} \bar{v} \mathrm{O}_{2}$ giảm thấp so với trước hoặc biến đổi ngoài giới hạn bình thường thì cần phải có can thiệp điều trị kịp thời (bảng 2).

Bảng 2. Vai trò chỉ số $\mathrm{S} \bar{v} \mathrm{O}_{2}$ trong đánh giá biến đổi huyết áp

\begin{tabular}{|c|c|c|}
\hline Biến cố & $\begin{array}{c}\text { Tụt } \mathrm{HA}+\mathrm{SV} \mathrm{O}_{2} \\
\text { bình thường }\end{array}$ & $\begin{array}{l}\text { Tụt } \mathrm{HA}+\mathrm{S} \bar{v} \mathrm{O}_{2} \\
\text { giảm thấp }\end{array}$ \\
\hline Huyết áp & HA giảm $20 \mathrm{mmHg}$ & HA giảm $20 \mathrm{mmHg}$ \\
\hline $\mathrm{S} \overline{\mathrm{V}} \mathrm{O}_{2}$ & $\mathrm{~S} \overline{\mathrm{v}} \mathrm{O}_{2}=70 \%$ & $\mathrm{~S} \overline{\mathrm{V}} \mathrm{O}_{2}=45 \%$ \\
\hline $\begin{array}{l}\text { Chẩn } \\
\text { đoán }\end{array}$ & HA đáp ứng nhu cầu & $\begin{array}{l}\text { HA không đáp ứng } \\
\text { nhu cầu }\end{array}$ \\
\hline Điều trị & Không can thiệp & Cần điều trị kịp thời \\
\hline
\end{tabular}

Giá trị bình thường của cung lượng tim $\mathrm{CO}$ thường phản ánh tình trạng cung cấp oxy đầy đủ cho mô cơ quan. Tuy nhiên, cung lượng tim chỉ là một biến số của phương trình cân bằng cung - cầu oxy sau: $\mathrm{VO}_{2}=\mathrm{CO} \times \mathrm{Hb} \times 13,8\left(\mathrm{SaO}_{2}-\mathrm{SvO}_{2}\right)$

Cung lượng tim không cung cấp thông tin về khả năng đáp ứng oxy đầy đủ theo nhu cầu tiêu thụ của mô. Khi cung lượng tim đạt 6 lít/phút nhưng giá trị bão hòa oxy máu tĩnh mạch trộn $\mathrm{S} \overline{\mathrm{V}} \mathrm{O}_{2}$ đo trong cùng thời điểm giảm thấp bất thường là dấu chỉ điểm gợi ý người thầy thuốc phải thăm khám kỹ hơn và/hoặc cần can thiệp điều trị kịp thời.

Ngược lại, khi cung lượng tim giảm thấp thường biểu thị tình trạng cung cấp oxy không đầy đủ cho mô cơ quan. Tuy nhiên, nếu giá trị $\mathrm{S} \mathrm{O}_{2}$ đo được trong cùng thời điểm còn duy trì giới hạn bình thường (bệnh nhân hạ thân nhiệt), thì với cung lượng tim 2,1 lít/phút vẫn đáp ứng đầy đủ nhu cầu tiêu thụ oxy của mô. Khuyến cáo không cần thiết can thiệp điều trị trong trường hợp cung lượng tim giảm thấp nhưng có giá trị $\mathrm{S} \overline{\mathrm{V}} \mathrm{O}_{2}$ đo được trong cùng thời điểm đang duy trì giới hạn bình thường (bảng 3 ).

Bảng 3. Vai trò chỉ số $\mathrm{S} \bar{v} \mathrm{O}_{2}$ trong đánh giá biến đổi cung lương tim

\begin{tabular}{|c|c|c|}
\hline $\begin{array}{l}\text { Biến } \\
\text { cố }\end{array}$ & $\begin{array}{c}\text { Tăng } \mathrm{CO}+\mathrm{S}^{\mathrm{V}} \mathrm{O}_{2} \\
\text { giảm thấp }\end{array}$ & $\begin{array}{c}\text { Giảm } \mathrm{CO}+\mathrm{SV} \mathrm{O}_{2} \\
\text { bình thường }\end{array}$ \\
\hline $\mathrm{CO}$ & $\mathrm{CO}=6$ lít/phút & $\mathrm{CO}=2,1$ lít/phút \\
\hline $\mathrm{S} \overline{\mathrm{V}} \mathrm{O}_{2}$ & $\mathrm{~S} \overline{\mathrm{V}} \mathrm{O}_{2}=45 \%$ & $\mathrm{~S} \overline{\mathrm{v}} \mathrm{O}_{2}=70 \%$ \\
\hline $\begin{array}{l}\text { Chẩn } \\
\text { đoán }\end{array}$ & $\begin{array}{l}\text { CO không đáp ứng } \\
\text { nhu cầu }\end{array}$ & $\begin{array}{l}\text { CO đáp ứng nhu } \\
\text { cầu }\end{array}$ \\
\hline $\begin{array}{c}\text { Điều } \\
\text { trị }\end{array}$ & $\begin{array}{l}\text { Cần can thiệp điều } \\
\text { trị kịp thời }\end{array}$ & Không can thiệp \\
\hline
\end{tabular}




\section{KẾT LUẬN}

Bão hòa oxy máu tĩnh mạch trộn $\mathrm{S}_{\mathrm{V}} \mathrm{O}_{2}$ là một chỉ điểm rất nhạy cảm ngay ở giai đoạn rất sớm khi người bệnh không ổn định huyết động và hô hấp đặc biệt cần thiết theo dõi bệnh nhân sau phẫu thuật tim vốn bị tổn thương trực tiếp hệ thống huyết động và đòi hỏi sự theo dõi liên tục cũng như cần sự can thiệp điều trị kịp thời. Việc theo dõi giá trị bão hòa oxy máu tĩnh mạch trộn $\mathrm{S}_{\mathrm{V}} \mathrm{O}_{2}$, vì vậy, giúp người thầy thuốc đánh giá chính xác tình trạng huyết động của người bệnh và đưa ra các liệu pháp điều trị phù hợp cho bệnh nhân sớm hơn so với các phương pháp kinh điển trước đây trong lĩnh vực chẩn đoán và điều trị. Một cách tổng quát, theo dõi bão hòa oxy máu tĩnh mạch tộn $\mathrm{S} \bar{v} \mathrm{O}_{2}$ là rất hữu ích trong lĩnh vực hồi sức huyết động với các vai trò là: 1) Hệ thống theo dõi và cảnh báo sớm tình trạng huyết động người bệnh; 2) Hướng dẫn để điều chỉnh và đánh giá liệu pháp điều trị; 3 ) Phương tiện để phân tích những biến đổi khác trên người bệnh.

Theo dõi bão hòa oxy máu tĩnh mạch trộn $\mathrm{SV} \mathrm{O}_{2}$ đặc biệt có ý nghĩa ở bệnh nhân có sự thiếu hụt khả năng dự trữ của tim. Khi suy tim, cung lượng tim giảm, cơ thể bù trừ bằng cách tăng khả năng phân tách oxy để đáp ứng với nhu cầu tiêu thụ oxy và biểu hiện chỉ điểm là giá trị của $S \bar{V} \mathrm{O}_{2}$ giảm thấp. Liệu pháp điều trị kịp thời tình trạng suy tim giúp cải thiện chức năng và đề phòng xảy ra các biến cố lâm sàng. Giá trị của chỉ số $\mathrm{SV} \mathrm{O}_{2}$ thay đổi liên quan đến thay đổi của các yếu tố đi kèm như bão hòa oxy động mạch $\mathrm{SaO}_{2}$, nồng độ hemoglobin, sự tiêu thụ oxy $\mathrm{VO}_{2}$ và cung lượng tim CO. Bão hòa oxy máu tĩnh mạch trộn $S \bar{v} \mathrm{O}_{2}$ giảm có nghĩa là do giảm cung lượng tim hoặc do tăng tiêu thụ oxy mất bù. Trong thực hành lâm sàng, khi giá trị của chỉ số $\mathrm{S} \overline{\mathrm{V}} \mathrm{O}_{2}$ biến đổi khoảng $10 \%$ so với giá trị bình thường là dấu hiệu cần phải can thiệp về huyết động. Bão hòa oxy máu tĩnh mạch trộn $\mathrm{S} \mathrm{O}_{2}<60 \%$ biểu thị tình trạng cơ thể sử dụng đáng kể khả năng dự trữ và sự phân tách oxy. Giá trị hòa oxy mãu tĩnh mạch trộn $\mathrm{S}_{\bar{V}} \mathrm{O}_{2}<40 \%$ biểu thị tình trạng thiếu oxy mô nặng nguy cơ đe dọa tính mạng người bệnh.

Tuy nhiên, để đánh giá quá trình oxy hóa ở mô cơ quan đòi hỏi người thầy thuốc phải thăm khám và đánh giá tất cả các thông số liên quan đến cân bằng cung - cầu oxy của cơ thể. Giá trị bão hòa oxy máu tĩnh mạch trộn $\mathrm{S} \bar{v} \mathrm{O}_{2}$ không phản ánh những biến đổi của bất kỳ thông số nào của phương trình cân bằng cung - cầu oxy bao gồm khả năng vận chuyển oxy $\mathrm{DO}_{2}$ của cơ thể và nhu cầu tiêu thụ oxy $\mathrm{VO}_{2}$ của mô. Tuy nhiên, khác với những thông số nói trên, bão hòa oxy máu tĩnh mạch trộn $\mathrm{SV}_{\mathrm{V}} \mathrm{O}_{2}$ là chỉ số giá trị đánh giá những biến đổi về mối tương quan tổng thể giữa khả năng cung ứng $\mathrm{DO}_{2}$ và nhu cầu tiêu thụ oxy $\mathrm{VO}_{2}$ của cơ thể; hơn nữa, bão hòa oxy máu tĩnh mạch trộn $\mathrm{S} \mathrm{O}_{2}$ là chỉ số có thể đo lường được một cách đơn giản và chính xác trong thực hành lâm sàng. Theo dõi bão hòa oxy máu tĩnh mạch trộn $\mathrm{S} \mathrm{O}_{2}$ không thay thế các thông số huyết động khác nhưng là phương tiện bổ sung giúp đánh giá quá trình oxy hóa xảy ra trong cơ thể qua đó có vai trò cảnh báo sớm tình trạng huyết động của người bệnh và hướng dẫn liệu pháp điều trị kịp thời và hiệu quả.

\section{TÀI LIỆU THAM KHẢO}

1. Baele PL, McMichan JC, Marsh HM, et al. (2012), Continuous monitoring of mixed venous oxygen saturation in critically ill patients. Anesth Analg 2012; 61(6):513-517.

2. Birman H, Haq A, Hew E, Aberman A. (2004), Continuous monitoring of mixed venous oxygen saturation in hemodynamically unstable patients. Chest 2004; 86(5):753-756.

3. De La Rocha AG, Edmonds JF, Williams WG, et al. (2008), Importance of mixed venous oxygen saturation in the care of critically ill patients. Can J Surg. 2008; 21(3):227-229.

4. Gore JM, Sloan K. (2004), Use of continuous monitoring of mixed venous saturation in the coronary care unit. Chest 2004; 86(5):757-761.

5. Jamieson WRE, Turnbull KW, Larrieu AJ, et al. (2012), Continuous monitoring of mixed venous oxygen saturation in cardiac surgery. Can J Surg. 2012; 25(5):538-43.

6. Martin WE, Cheung PW, Johnson CC, Wong KC. (2003), Continuous monitoring of mixed venous oxygen saturation in man. Anesth Anal. 2003; 52(5):784-93.

7. Sandham J. D. and al (2007), "A randomized controlled trial of the use of pulmonary artery catheters in high-risk surgical patients", New England Journal of Medicine.

8. Schmidt CR, Frank LP, Forsythe SB, Estafanous FG. (2004), Continuous $\mathrm{SvO} 2$ measurement and oxygen transport patterns in cardiac surgery patients. Critical Care Med. 2004; 12(6):523-527.

9. Sottile FD, Durbin CG, Hoyt JW, et al. (2012), Evaluation of pulmonary artery oximetry as a predictor of cardiac output. Anesth. 2012; 57(3):AI27. 